\title{
Pembelajaran probing prompting untuk meningkatkan berpikir kritis siswa anggota kelompok ilmiah remaja
}

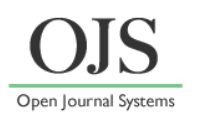

Megasari*, Agus Sundaryono, M. Lutfi Firdaus

Pascasarjana Pendidikan IPA FKIP Universitas Bengkulu, Bengkulu

*Email: megasari259@gmail.com

\begin{abstract}
ABSTRAK
Kegiatan ilmiah mahasiswa dapat dilakukan melalui kegiatan ekstrakurikuler Kelompok Ilmiah Remaja (KIR). Anggota KIR diharuskan memiliki keterampilan berpikir kritis dalam mencari topik untuk menulis makalah ilmiah. Salah satu metode pembelajaran yang dapat dilakukan untuk meningkatkan pemikiran kritis siswa KIR adalah dengan mempelajari instruksi yang dibantu oleh video-assisted. Sebuah eksperimen semu dengan desain desain one pretest-posttest dilakukan untuk mengukur tingkat berpikir kritis anggota KIR dengan memberikan pretest sebelum mempelajari probing yang mendorong tes videoaided dan post setelah belajar dorongan video-assisted probing. Analisis data dilakukan dengan menggunakan uji efektivitas dan uji Wilcoxon. Hasil data dengan efek pengukuran nilai efek diperoleh E> 0,8 yang berarti ada peningkatan berpikir kritis sebelum dan sesudah belajar. Uji Wilcoxon diperoleh nilai $\mathrm{p}(\mathrm{Z})=0,0344$. Nilai $\mathrm{p}(\mathrm{Z})<0,05$ yang berarti kemampuan berpikir kritis siswa meningkat dari pretest ke posttest.
\end{abstract}

Kata kunci: Probing prompting; berpikir kritis; kelompok ilmiah remaja.

\section{PENDAHULUAN}

Sekolah merupakan lingkungan yang sengaja dibentuk untuk mendidik generasi muda ke arah tujuan tertentu, terutama untuk membekali dengan pengetahuan dan kecakapan hidup yang dibutuhkan di kemudian hari. Sebagai lembaga yang sengaja di bentuk untuk mendidik generasi muda, sekolah mempunyai tanggung jawab untuk menghasilkan lulusan yang berkualitas dan mempunyai kontribusi yang besar bagi kemajuan bangsa melalui proses pendidikan yang dijalankan. Pasal 3 UndangUndang Nomor 20 Tahun 2003 tentang Sistem Pendidikan Nasional menyebutkan bahwa pendidikan nasional bertujuan untuk berkembangnya potensi peserta didik agar menjadi manusia yang beriman dan bertakwa kepada Tuhan Yang Maha Esa, berakhlak mulia, sehat, berilmu, cakap, kreatif, mandiri, dan menjadi warga negara yang demokratis serta bertanggung jawab. Pengembangan potensi peserta didik sebagaimana dimaksud dalam tujuan pendidikan nasional tersebut dapat diwujudkan melalui kegiatan ekstrakurikuler.
Ekstrakurikuler adalah kegiatan pendidikan yang dilakukan oleh peserta didik di luar jam belajar kurikulum standar sebagai perluasan dari kegiatan kurikulum dan dilakukan di bawah bimbingan sekolah dengan tujuan untuk mengembangkan kepribadian, bakat, minat, dan kemampuan peserta didik yang lebih luas atau di luar minat yang dikembangkan oleh kurikulum.

Salah satu kegiatan ekstrakurikuler berbentuk karya ilmiah; meliputi Kegiatan Ilmiah Remaja (KIR), kegiatan penguasaan keilmuan dan kemampuan akademik, penelitian, dan lainnya. Serangkaian kegiatan KIR untuk menghasilkan karya ilmiah (Santoso, 2017). Penyusunan karya ilmiah sebagai kegiatan penuangan gagasan, ide, pengetahuan tidak serta merta menjadi karya sesuai kategori keilmuannya. Karya yang dituangkan memerlukan proses tertentu (Ambarwati, 2012).

Proses penulisan karya ilmiah sebagaimana menulis pada umumnya membutuhkan perencanaan agar jalan pikiran terarah. Perencanaan karya ilmiah disebut juga dengan tahap pramenulis (Ambarwati, 2012). 
Lebih dari $70 \%$ waktu dalam menulis terletak pada tahap pramenulis (Sukino, 2010).

Pada tahap pramenulis yang harus dilakukan adalah menentukan topik, menetapkan tujuan, mengumpulkan bahan dan membuat kerangka karangan. Pada tahap ini anggota kelompok ilmiah dituntut untuk memiliki kemampuan berpikir kritis dalam melihat fenomena alam dan fenomena sosial yang terjadi disekitarnya. Mampu berpikir untuk melihat pengaruh fenomena alam dan fenomena sosial tersebut bagi kehidupan manusia, serta mampu menemukan ide - ide sebagai hasil dari berpikir kritis untuk dituangkan kedalam karya ilmiah.

Salah satu kontributor terkenal bagi pengembangan budaya berpikir kritis adalah Robert H. Ennis dalam menyatakan bahwa berpikir kritis adalah berpikir reflektif yang masuk akal yang berfokus untuk memutuskan apa yang harus diyakini atau dilakukan. Menurut Ennis (1991: 20), terdapat enam unsur dasar dalam berpikir kritis yang disingkat menjadi FRISCO, yaitu:

- F (Focus), yaitu memfokuskan pertanyaan atau isu yang tersedia untuk membuat sebuah keputusan tentang apa yang diyakini

- $\mathrm{R}$ (Reason), yaitu mengetahui alasan-alasan yang mendukung atau melawan putusanputusan yang dibuat berdasarkan situasi dan fakta yang relevan,

- I (Inference), yaitu membuat kesimpulan yang beralasan atau menyungguhkan. Bagian penting dari langkah penyimpulan ini adalah mengidentifikasi asumsi dan mencari pemecahan, pertimbangan dari interpretasi akan situasi dan bukti,

- S (Situation), yaitu memahami situasi dan selalu menjaga situasi dalam berpikir akan membantu memperjelas pertanyaan dan mengetahui arti istilah - istilah kunci bagianbagian yang relevan sebagai pendukung,

- C (Clarity), yaitu menjelaskan arti atau istilah-istilah yang digunakan,

- O (Overview), yaitu meninjau kembali dan meneliti secara menyeluruh keputusan yang diambil.

\begin{tabular}{lllr}
\multicolumn{1}{c}{ Ennis } & (1991) & \multicolumn{2}{r}{ mengungkapkan } \\
keterampilan & berpikir & kritis & yang \\
dikelompokkan & ke dalam & lima & aspek
\end{tabular}

keterampilan, yaitu: a) memberikan penjelasan sederhana, b) membangun keterampilan dasar, c) menyimpulkan, d) memberikan penjelasan lebih lanjut, e) mengatur strategi dan taktik.

KIR SMA Negeri 1 Bengkulu Tengah adalah wadah bagi para siswa yang memiliki perhatian besar pada pengembangan sikap ilmiah, kejujuran dalam menuangkan ide-ide hasil pengamatan terhadap fenomena alam dan fenomena sosial yang ditemui dengan metode yang sistematis, obyektif, rasional dan berprosedur. Oleh karena itu perlu diupayakan suatu strategi pembelajaran KIR yang dapat meningkatkan keterampilan berpikir siswa sehingga mampu membudayakan dan menumbuhkan minat / bakat dalam pengkajian dan pengembangan ilmu dan pengetahuan. Salah satu metode pembelajaran tersebut adalah probing prompting.

Pembelajaran probing prompting adalah pembelajaran dengan cara guru menyajikan serangkaian pertanyaan yang sifatnya menuntun dan menggali sehingga terjadi proses berpikir yang mengaitkan pengetahuan tiap siswa dan pengalamannya dengan pengetahuan baru yang sedang dipelajari (Suherman, 2008).

Menurut (Fajar dan Wanarti, 2014) sintak pembelajaran kooperatif tipe probing promting terdiri dari 7 langkah:

- Guru menghadapkan siswa pada situasi baru, misalkan dengan memperhatikan gambar, rumus atau situasi lainnya yang mengandung permasalahan.

- Menunggu beberapa saat untuk memberikan kesempatan kepada siswa untuk merumuskan jawaban atau melakukan diskusi kecil dalam merumuskannya.

- Guru mengajukan persoalan kepada siswa yang sesuai dengan tujuan pembelajaran.

- Menunggu beberapa saat untuk memberikan kesempatan kepada siswa untuk merumuskan jawaban atau melakukan diskusi kecil dalam merumuskannya.

- Menunjuk salah satu siswa untuk menjawab pertanyaan.

- Jika jawabannya tepat maka guru meminta tanggapan kepada siswa lain tentang jawaban untuk meyakinkan bahwa seluruh siswa terlibat dalam kegiatan yang sedang berlangsung. Namun, jika siswa tersebut 
mengalami kemacetan jawab dalam hal ini jawaban yang diberikan kurang tepat, tidak tepat, atau diam, maka guru mengajukan pertanyaan-pertanyaan lain yang jawabannya merupakan petunjuk jalan penyelesaian jawaban. Lalu dilanjutkan dengan pertanyaan yang menuntun siswa berpikir pada tingkat yang lebih tinggi, sampai dapat menjawab pertanyaan sesuai dengan kompetensi dasar atau indikator. Pertanyaan yang dilakukan pada langkah keenam ini sebaiknya diajukan pada beberapa siswa yang berbeda agar seluruh siswa terlibat dalam seluruh kegiatan probing prompting.

- Guru mengajukan pertanyaan akhir pada siswa yang berbeda untuk lebih menekankan bahwa indikator tersebut benar- benar telah dipahami seluruh siswa.

Adapun kelebihan model pembelajaran probing prompting antara lain adalah mendorong siswa aktif berpikir, memberi kesempatan kepada siswa untuk menanyakan hal-hal yang kurang jelas sehingga guru dapat menjelaskan kembali, perbedaan pendapat antara siswa dapat dikompromikan atau diarahkan pada suatu diskusi, pertanyaan dapat menarik dan memusatkan perhatian siswa, sekalipun ketika itu siswa sedang ribut, dan mengantuk, dapat mengulang kembali (review) bahan pelajaran yang lampau, mengembangkan keberanian dan keterampilan siswa dalam menjawab dan mengemukakan pendapat.

Salah satu topik penelitian yang gencar dilakukan yaitu tentang energi meliputi upaya untuk mencari sumber-sumber energi terbarukan yang ramah lingkungan. Hal ini karena energi sangat dibutuhkan dalam kehidupan manusia. Upaya mengembangkan sumber energi terbarukan untuk mengatasi kelangkaan sumber energi juga sepatutnya diketahui generasi muda terutama siswa.

Penelitian ini bertujuan untuk mengukur kemampuan berfikir kritis siswa anggota KIR di SMAN 1 Bengkulu Tengah sebelum dan sesudah pembelajaran probing prompting berbantuan video.

\section{METODE PENELITIAN}

Jenis penelitian quasi eksperimen (eksperimen semu) dengan desain One group Pretest-posttest design menggunakan metode probing prompting. Penelitian dilaksanakan pada siswa yang mengikuti kegiatan ekstrakurikuler KIR di SMAN 1 Bengkulu Tengah Tahun Pelajaran 2016/2017.

Penelitian memiliki variabel terikat yaitu kemampuan berfikir kritis siswa dan variabel bebas yaitu pembelajaran probing prompting berbantuan media video.

Siswa anggota KIR dibagi menjadi dua. Setengah untuk uji coba soal dan setengah lagi untuk penelitian. Pengambilan data dilakukan melalui pretes dan posttes. Soal-soal yang digunakan dalam pretes dan posttest merupakan soal-soal berfikir kritis menurut Ennis dengan dimensi :

- Memberikan penjelasan sederhana (Elementary Clarification)

- Membangun keterampilan dasar (Basic Support)

- Menyimpulkan (Inference)

- Memberikan penjelasan lanjut

- Mengatur strategi dan teknik

Soal-soal yang telah dibuat sebelum diujicobakan, dilakukan uji validasi terlebih dahulu oleh dosen pendidikan kimia dan guru kimia senior. Setelah itu soal diujicobakan kepada setengah anggota KIR. Data yang diperoleh dianalisis untuk mengetahui validitas dan reliabilitas soal.

Analisis yang dilakukan dalam implementasi pembelajaran ini adalah uji non parametrik dikarenakan jumlah sampel yang kecil yaitu sebanyak 4 orang anggota KIR SMAN 1 Bengkulu Tengah T.P 2016/2017.

\section{Uji Validitas}

Uji validitas untuk mengetahui apakah instrumen benar-benar mengukur objek yang akan diukur. Menurut Yusuf (2014). Uji ini dilakukan dengan menggunakan korelasi biserial dengan rumus: 


$$
r_{p b i s}=\frac{M p-M t}{S D t} \sqrt{\frac{p}{q}}
$$

Keterangan:

$\mathrm{r}_{\mathrm{pbis}}=$ koefisien korelasi biserial

$\mathrm{Mp}=$ rerata skor dari subjek yang menjawab benar dicari validitasnya.

$\mathrm{Mt}=$ rerata total

SDt $=$ standar deviasi dari skor total

$\mathrm{p}=$ Proporsi responden yang menjawab benar butir soal yang di cari

$\mathrm{q}=$ proporsi responden yang menjawab salah butir soal yang dicari $(\mathrm{q}=1-\mathrm{p})$

Jika harga $r_{\text {pbis }}>r_{\text {tabel }}$ dengan $\alpha=5 \%$ maka soal dianggap valid. Analisa uji validitas juga dapat dilakukan menggunakan SPSS 16.0.

\section{Uji Reliabilitas}

Reliabilitas adalah taraf sampai dimana suatu tes mampu menunjukkan konsistensi hasil pengukurannya yang diperlihatkan dalam taraf ketepatan dan ketelitian hasil. Instrumen diukur dengan menggunakan persamaan Gutmann dan Kuder Richardson, formula KR20 sebagai berikut:

Keterangan:

$$
r_{t t}=\left[\frac{n}{n-1}\right] \frac{S D^{2} t-\sum p q}{S D t^{2}}
$$

$\mathrm{rtt}=$ koefisien reabilitas keseluruhan instrumen

$\mathrm{n} \quad=$ jumlah butir dalam keseluruhan instrumen

$\mathrm{SD}^{2} \mathrm{t}=$ Varian keseluruhan instrumen

$\mathrm{p}=$ proporsi jumlah responden (dalam persen) yang menjawab tiap butir dengan benar

$\mathrm{q}=$ proporsi jumlah responden (dalam persen yang gagal menjawab tiap instrument)

$\sum \mathrm{pq}=$ jumlah perkalian $\mathrm{p}$ dan $\mathrm{q}$ untuk semua butir

Analisis reliabilitas juga dapat menggunakan rumus Alpha. Data diolah menggunakan SPSS 16.0
Tabel 1.Kriteria realibilitas

\begin{tabular}{ll}
\hline Nilai reliabilitas & $\begin{array}{l}\text { Kriteri } \\
\text { reliabilitas }\end{array}$ \\
\hline $\mathbf{R}<\mathbf{0 , 2 0}$ & Tidak ada \\
$\mathbf{0 , 2 1}-\mathbf{0 , 4 0}$ & Rendah \\
$\mathbf{0 , 4 1}-\mathbf{0 . 7 0}$ & Sedang \\
$\mathbf{0 , 7 1}-\mathbf{0 , 9 0}$ & Tinggi \\
$\mathbf{0 , 9 1}-\mathbf{1 , 0 0}$ & Sempurna \\
\hline & (Kinkin, 2010:13).
\end{tabular}

Setelah soal valid maka dilakukan penelitian kepada setengah anggota kIR yang lain. Data yang diperoleh dianalisis menggunakan Effek Size dan Uji Wilcoxon untuk melihat apakah terdapat peningkatan berfikir kritis siswa sebelum dan sesudah pembelajaran probing prompting berbantuan media video.

Effect Size

$$
E=\frac{\bar{x}_{2}-\bar{x}_{1}}{S}
$$

Keterangan :

$\bar{x}_{1}=$ Rata-rata nilai pretest

$\bar{x}_{2}=$ Rata-rata nilai post test

$S=$ standar deviasi dari post test

Kriteria pengujian,

$0<\mathrm{E}=$ Efek peningkatan dari pretest

$<0,2 \quad$ ke postest kecil

$0,2<\mathrm{E}=$ Efek peningkatan dari pretest

$<0,8 \quad$ ke postest sedang

$\mathrm{E}>0.8=$ Efek peningkatan dari pretest ke postest besar

Uji Wilcoxon

$Z=\frac{T-\frac{n(n+1))}{4}}{\sqrt{\frac{n(n+1)(2 n+1)}{24}}}$

(Santoso, 2010)

Keterangan:

$\mathrm{N}=$ Banyak data yang berubah setelah diberi perlakuan berbeda

$\mathrm{T}=$ jumlah renking dari nilai selisih yng negatif (apabila banyaknya selisih yang positif lebih banyak dari banyaknya selisih negatif)

$=$ jumlah ranking dari nilai selisih yang positif (apabila banyaknya selisih yang negatif > banyaknya selisih yang positif) 
Signifikansi, nilai $\mathrm{Z}$ dibandingkan dengan tabel kurva normal,

Ho ditolak bila Zhitung $\geq Z$ tabel, Ho diterima bila $\mathrm{Z}$ hitung $<\mathrm{Z}$ tabel

\section{HASIL DAN PEMBAHASAN}

Anggota KIR berjumlah 8 orang yang dibagi dua, setengahnya untuk tes uji coba soal dan setengah lagi untuk dijadikan subjek penelitian. Kedelapan siswa KIR tersebut berasal dari kelas dengan jurusan berbeda yaitu kelas peminatan IPA, IPS dan Bahasa.

Sebelum digunakan dalam penelitian, soal-soal tersebut terlebih dahulu di ujicobakan kepada setengah anggota KIR sebanyak 4 orang untuk melihat validitas dan realibilitasnya. Data yang diperoleh diuji menggunakan SPSS 16.0 (Lampiran 27 dan 28). Dari 10 soal yang di ujicobakan ternyata sebanyak 6 soal yang valid dan nilai realibilitas sebagai berikut:

Tabel 2. Uji reliabilitas Instrumen

\begin{tabular}{lll}
\hline Instrumen & Alpha & Keterangan \\
\hline Tes & 0,990 & Reliabilitas tinggi \\
\hline
\end{tabular}

Koefisien reliabilitas alpha sebesar 0,990 menunjukkan bahwa instrument dinyatakan reliable untuk mengukur berfikir kritis siswa dari aspek kognitif.

Tahap selanjutnya adalah melakukan penelitian terhadap setengah lagi dari anggota KIR yaitu berjumlah 4 orang. Pembelajaran yang dilakukan menggunakan metode probing prompting berbantuan media video. Penelitian dimulai dengan memberikan soal pretest kepada siswa. Pretest ini dimaksudkan untuk mengetahui tingkat berfikir kritis awal siswa KIR tentang energi terbarukan.

Setelah lembar jawaban dikumpul, dilanjutkan dengan melakukan pembelajaran dengan teknik probing yaitu dengan mengajukan pertanyaan - pertanyaan mengenai energi yang dipakai sehari- hari, asal-usulnya, dampaknya, dan perlukah mencari sumber - sumber energi lain. Pertanyaan dalam proses probing bertujuan untuk menggali dan melacak pengetahuan awal yang telah dimiliki siswa (David dkk, 2009)
Pertanyaan - pertanyaan tersebut ada yang bisa dijawab beberapa siswa secara garis besar saja dan ada juga pertanyaan yang tidak bisa dijawab siswa.

Tabel 3. Nilai Pretes dan Posttes

\begin{tabular}{lll}
\hline Inisial Nama & Nilai pretest & Nilai posttes \\
\hline AP & 31 & 44 \\
CR & 18 & 25 \\
LN & 24 & 35 \\
AZ & 10 & 14 \\
Rata-rata & $\mathbf{2 0 , 7 5}$ & $\mathbf{2 9 , 5 0}$ \\
\hline
\end{tabular}

Selanjutnya penanyangan video pembelajaran yang telah dibuat sebelumnya. Semua siswa terfokus melihat video. Sesaat setelah video selesai ditayangkan banyak yang mengajukan pertanyaan sebagai tanda ketertarikan siswa KIR terhadap materi energi terbarukan.

Selanjutnya melakukan proses pembelajaran dengan teknik prompting. Pertanyaan pada teknik prompting bertujuan mengarahkan atau menuntut yakni pertanyaan yang melibatkan penggunaan petunjuk / isyarat untuk membantu siswa menjawab dengan benar (David dkk, 2009). Guru berusaha mengajukan pertanyaan- pertanyaan sederhana yang dapat menuntun dan mengarahkan siswa agar dapat menjelaskan tentang energi terbarukan. Lalu guru mereview informasi tentang energi terbarukan yang telah diketahui siswa. Setelah diskusi selesai dilakukan proses postest kepada siswa untuk mengetahui perbedaan tingkat berfikir kritis siswa sebelum dan sesudah pembelajaran. Nilai pretest dan posttest dapat di lihat pada tabel berikut.

Hasil postest yang dibandingkan dengan hasil pretest menunjukkan bahwa terjadi peningkatan berfikir kritis. Nilai rata-rata pretest pada penelitian ini adalah 20,75 sedangkan nilai rata-rata postest adalah 29,5 . 


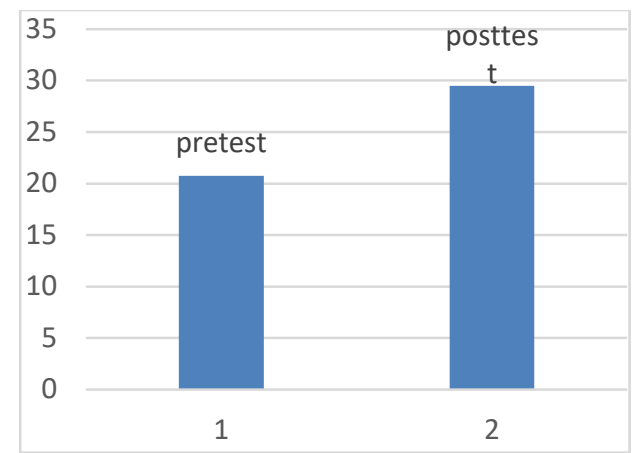

Gambar 1. Perbandingan nilai rata-rata berfikir kritis siswa sebelum dan sesudah pembelajaran probing prompting dengan media video

Grafik pada Gambar 1 menunjukkan adanya peningkatan berfikir kritis siswa yang dilihat dari aspek kognitif setelah menyelesaikan soal-soal dengan kriteri berfikir Ennis siswa. Melihat peningkatan berfikir kritis siswa KIR sebelum dan sesudah pembelajaran berbantuan video dengan cara menghitung efek size. Dari hasil perhitungan diperoleh $E=1,13$. Nilai $E>0,8$ yang berarti terdapat peningkatan berfikir kritis sebelum dan sesudah pembelajaran berbantuan video (Naga, 2008).

Uji hipotesis dilakukan dengan uji Wilcoxon. Diperoleh $\mathrm{Z}=-1,826$. Nilai tersebut dicocokkan dalam daftar kurva normal dan diperoleh $\mathrm{p}(\mathrm{Z})=0,0344$. Nilai $\mathrm{p}(\mathrm{Z})<0,05$. Maka Ho ditolak dan H1 diterima, berarti kemampuan berpikir kritis siswa meningkat dari pretes ke posttest.

Pembelajaran probing prompting menuntut siswa untuk lebih aktif dalam memperoleh suatu konsep karena siswa akan berusaha untuk mengembangkan nalarnya dalam menjawab pertanyaan yang diajukan dalam pembelajaran. Pembelajaran probing prompting memposisikan guru untuk dapat menyajikan serangkaian pertanyaan yang sifatnya menuntun dan menggali sehingga terjadi proses berfikir siswa terhadap pengetahuan baru yang sedang dipelajari (Diasputri, 2013). Penggunaan media video secara signifikan dapat meningkatkan keterampilan mengajukan pertanyaan, dan lebih meningkatkan penguasaan konsep serta keterampilan berpikir kritis siswa SMA (Syukur, 2013.

\section{KESIMPULAN}

Terdapat peningkatan kemampuan berfikir kritis siswa anggota KIR sesudah pembelajaran probing prompting dengan bantuan media video. Pembelajaran probing prompting dengan media video dapat digunakan pada materi lain yang bersifat konsep.

\section{DAFTAR PUSTAKA}

Ambarwati, Ririn. (2012) Kemampuan Menulis Perencanaan Karya Ilmiah Siswa Kelas XII Jurusan Bahasa di SMA Negeri 1 Bantur Tahun Ajaran 2011-2012. Malang: Universitas Negeri Malang. Program Studi Pendidikan Bahasa, Sastra Indonesia dan Daerah.

Ennis, Robert. (1991). Critical Thinking: A Streamlined Conception. University of Illinios: Artikel Teaching Philosophy;

David A J. (2009). Methods for Teaching. Terjemahan Achmad Fawaid. Yogyakarta: Pustaka Pelajar.

Diasputri A, Sri.N, Warlan S. (2013). Pengaruh Model Pembelajaran Probing Promting Berbantuan Lembar kerja Berstruktur Terhadap Hasil Belajar. Jurnal Inovasi Pendidikan Kimia; Vol 7 No1: 11031111.

Fajar,F dan Winarti,P. (2014). Pengaruh Metode Pembelajaran Tanya Jawab ProbingPrompting Terhadap Hasil Belajar Siswa Pada Standar Kompetensi Menerapkan Dasar - Dasar elektronika Kelas X AV Di SMKN 2 Surabaya. Jurnal Pendidkan Teknik Elektro ; Vol.03 No.01. 89-96

Kinkin. (2010). Analisis Tes dan Butir Soal. Pontianak: Wanda Putra Persada.

Naga, DS. (2008) 64 Rumus Terapan Probabilitas dan Sekor pada Hipotesis Statistika. Jakarta: Grasindo.

Santoso, H. (2017) Kontribusi Perpustakaan Sekolah Dalam Menunjang Kegiatan Kelompok Ilmiah Remaja (KIR). http://library.um.ac.id

Santoso,S.(2010). Statistik Non Parametrik. Jakarta: PT. Elex Media Komputindo. 
Suherman, E. (2008). Model Belajar dan Pembelajaran Berorientasi Kompetensi Siswa. Jurnal Pendiidikan dan Budaya Educare. Vol.5 No.5 ISSN: 1412-579X

Sukino.(2010). Menulis Itu Mudah. Yogyakarta : Pustaka Populer.

Syukur A. (2013). Penggunaan Video Dalam Pembelajaran Materi Metabolisme Untuk Mengungkap Keterampilan Mengajukan Pertanyaan Dan Meningkatkan Keterampilan Berpikir Kritis Siswa SMA Kelas XII IPA. [Tesis]. Bandung: Universitas Pendidikan Indonesia.

Yusuf M. (2014) Metode Penelitian Kuantitatif, Kualitatif dan Penelitian Gabungan. Jakarta:Kencana. 